\title{
Microstructures, Textures and Mechanical Properties Evolution during Cold Drawing of Pure Mg
}

\author{
Yandang Qiao*, Xin Wang, Zuyan Liu, Erde Wang
}

National Key Laboratory for Precision Hot Processing of Metals, Harbin Institute of Technology, Harbin, China. Email: damo1366@163.com

Received May $15^{\text {th }}, 2013$; revised June $21^{\text {st }}, 2013$; accepted July $10^{\text {th }}, 2013$

Copyright (C) 2013 Yandang Qiao et al. This is an open access article distributed under the Creative Commons Attribution License, which permits unrestricted use, distribution, and reproduction in any medium, provided the original work is properly cited.

\begin{abstract}
Pure Mg wires with a maximum cumulative area reduction of $98 \%$ were obtained by successful cold drawing. Mechanical properties, microstructures and texture evolution of the as-drawn wires were investigated by tensile tests, transmission electron microscopy (TEM) and electron backscattering diffraction (EBSD). Depending on the mechanical properties and microstructure evolution, continuous dynamic recrystallization (DRX) had taken place during the cold drawing process. DRX during cold deformation has not been reported in other literatures before.
\end{abstract}

Keywords: Cold Drawing; Magnesium Alloys; Dynamic Recrystallization; TEM

\section{Introduction}

Magnesium alloys have potentially suitable applications in some automobile and electronics parts due to their excellent specific properties and low weight, so these materials have attracted significant interest [1]. Magnesium and its alloys show generally low ductility because of the few slip systems in hexagonal close-packed (HCP) lattice and so are categorized in hard plastic materials [2]. Nowadays, tension and compression tests at room temperature are the most common methods used to study room deformation behavior of $\mathrm{Mg}$ alloys, and the true strain is less than 0.5 [3-7]. Researches on severe plasticity deformation behaviors of $\mathrm{Mg}$ alloys at room temperature can be hardly seen in literatures.

It has been explained in $\mathrm{Mg}$ alloys [8-11] that new fine grain evolution can result from continuous DRX including twinning DRX and rotation DRX at ambient to moderate temperatures and, in contrast, from conventional (i.e. discontinuous) DRX including a nucleation of new grains and their larger-scale growth taking place under hot deformation. The reasons why the DRX mechanisms are changed by deformation conditions and how the mechanisms operated remained unclear. DRX of $\mathrm{Mg}$ and its alloys at low temperature have not been reported in other literatures.

In this article, a maximum cumulative area reduction of $98 \%$ corresponded to a true strain value of 3.86 was

\footnotetext{
*Corresponding author.
}

obtained by successful cold drawing, and evolutions of microstructure, mechanical properties and the deformation mechanism during severe cold deformation of pure Mg was investigated.

\section{Experimental Procedures}

The materials used in the present study are a hot drawn pure $\mathrm{Mg}(\mathrm{Mg} \geq 99.99 \%$, other alloying elements $\leq 0.01 \%)$ wire with a diameter of $2 \mathrm{~mm}$. Figure 1 shows the microstructure and the texture of the initial material consisted of equiaxed grains with a mean linear intercept grain size of $38 \pm 0.5 \mu \mathrm{m}$. Then it was followed by a successful cold drawing processing with each passed area reduction of $8 \% \sim 12 \%\left(\varphi=\left[1-\left(d_{n+1} / d_{n}\right)^{2}\right] \times 100 \%\right.$, where $n$ is the numbers of processing passes, $d$ is the diameter of wire and $\varphi$ is the area reduction of each pass.). The initial pure $\mathrm{Mg}$ wires were cold drawn to a maximum cumulative area reduction of $98 \%$

$\left(\phi=\left[1-\left(d_{n} / d_{0}\right)^{2}\right] \times 100 \%\right.$, where $\phi$ is the cumulative area reduction) which corresponded to a true strain value of 3.86 according to the relationship of $\varepsilon=\ln \left(d_{n} / d_{0}\right)^{2}$ (where $\boldsymbol{d}_{\boldsymbol{n}}$ is the wire diameter via $\mathrm{n}$ processing passes and $\boldsymbol{d}_{0}$ is the starting diameter.).

To investigate the mechanical properties, uniaxial tensile tests were carried out on the Instron 5569 at room temperature with a constant initial strain rate of $1.67 \times$ 

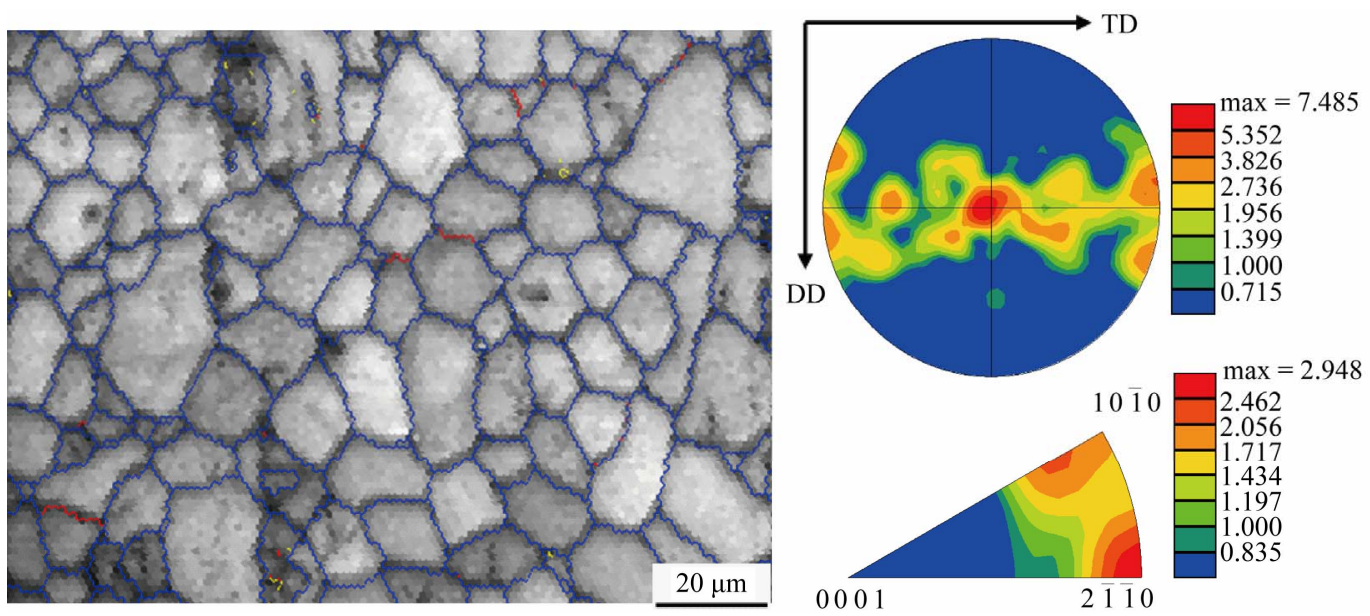

Figure 1. Microstructure and texture of the initial pure $\mathrm{Mg}$ wire. (The sample direction of the inverse pole figures is drawing direction).

$10^{-3} \cdot \mathrm{s}^{-1}$ and micro-hardness tests were carried out with pressure of $100 \mathrm{~N}$ and time of $15 \mathrm{~s}$ respectively.

Metallographic observations were identified by TECNAI 20 Transmission electron microscopy (TEM) and electron backscattering diffraction (EBSD) performed on JEOL 733 electron probe equipped with TSL OIM Analysis system, with the observation planes parallel to the drawing direction.

\section{Results}

\subsection{Microstructures}

Figure 2 displays the microstructures, misorientation distribution and grain size distribution charts of the asdrawn wires with different area reduction obtained by EBSD in the plane parallel to the drawing direction corresponding to the crystal reference system with the drawing direction, respectively. High-angle boundaries (HAB) angles with misorientations more than $15^{\circ}$ are delineated by black lines, while low-angle boundaries (LAB) angles in the range of $5^{\circ}-15^{\circ}$ by red lines and those in range of $2^{\circ}-5^{\circ}$ by yellow lines.

It can be seen that the grains became finer and finer while proportion of the $\mathrm{LAB}$ angles in range of $2^{\circ}-5^{\circ}$ and the $\mathrm{HAB}$ angles in range of $80^{\circ}-90^{\circ}$ declined with the drawing process, the $\mathrm{LAB}$ in range of $2^{\circ}-5^{\circ}$ corresponded to the deformation boundaries and the $\mathrm{HAB}$ in range of $80^{\circ}-90^{\circ}$ corresponded to the $\{11-20\}<10$ $11>$ twinning boundaries. When the cumulative area reduction smaller than $30 \%$, A large number of severely deformed zones composed of LAB angles were found in the microstructures and some initial grains still existed. The grain size distributions of the samples were decomposed into regions of coarse grains and fine grains. When the cumulative area reduction in the range of $40 \%$ to $50 \%$, only a few of LAB groups in range of $2^{\circ}-5^{\circ}$ can be found. While the cumulative area reduction exceeded $70 \%$, LAB groups totally disappeared; LAB existed in individual form. Microstructures of the samples were composed of almost only recrystallized grains with highangle boundaries. Finally grains size of the as-drawn wires was refined from $38 \mu \mathrm{m}$ into $6 \mu \mathrm{m}$ due to continuous DRX.

Figure 3 shows the microstructure evolution of pure $\mathrm{Mg}$ during cold drawing process obtained by TEM. When the area reduction is $15 \%$, form Figures 3(a) and (b) it can be seen that a great deal of parallel shear bands and $\{10-12\}$ twinning were observed in the microstructures. This evidenced that basal slip and $\{10-12\}$ twinning is the main deformation mechanisms during cold deformation of pure $\mathrm{Mg}$. Simultaneously some final grains with grain size of $0.5 \sim 2 \mu \mathrm{m}$ were observed in the severely deformed zones, as shown in Figure 3(c). When the area reduction is $30 \%$, the microstructure is almost the same as $15 \%$, the only difference is that the number of the parallel shear bands, twinning and the final grains increased, as shown in Figures 3(d)-(f). When the area reduction is $50 \%$, the number of the parallel shear bands and twinning decreased. Meanwhile, the number of the final grains increased, some small grains began to grow, as shown in Figure 3(g). With the cumulative area reduction increasing (specimens deformed to $70 \%$ and 90\%), wide parallel shear bands and twinning almost disappeared, the microstructure is composed of large recrystallized grains; Some slender shear bands and twinning was observed in the inside of the recrystallized grains, as shown in Figures 3(h) and (i).

\subsection{Texture Evolution}

Figure 4 shows the evolution of the pole figures and inverse pole figures of the as-drawn wires with area reduction. It is remarkable to note that the original wire has 

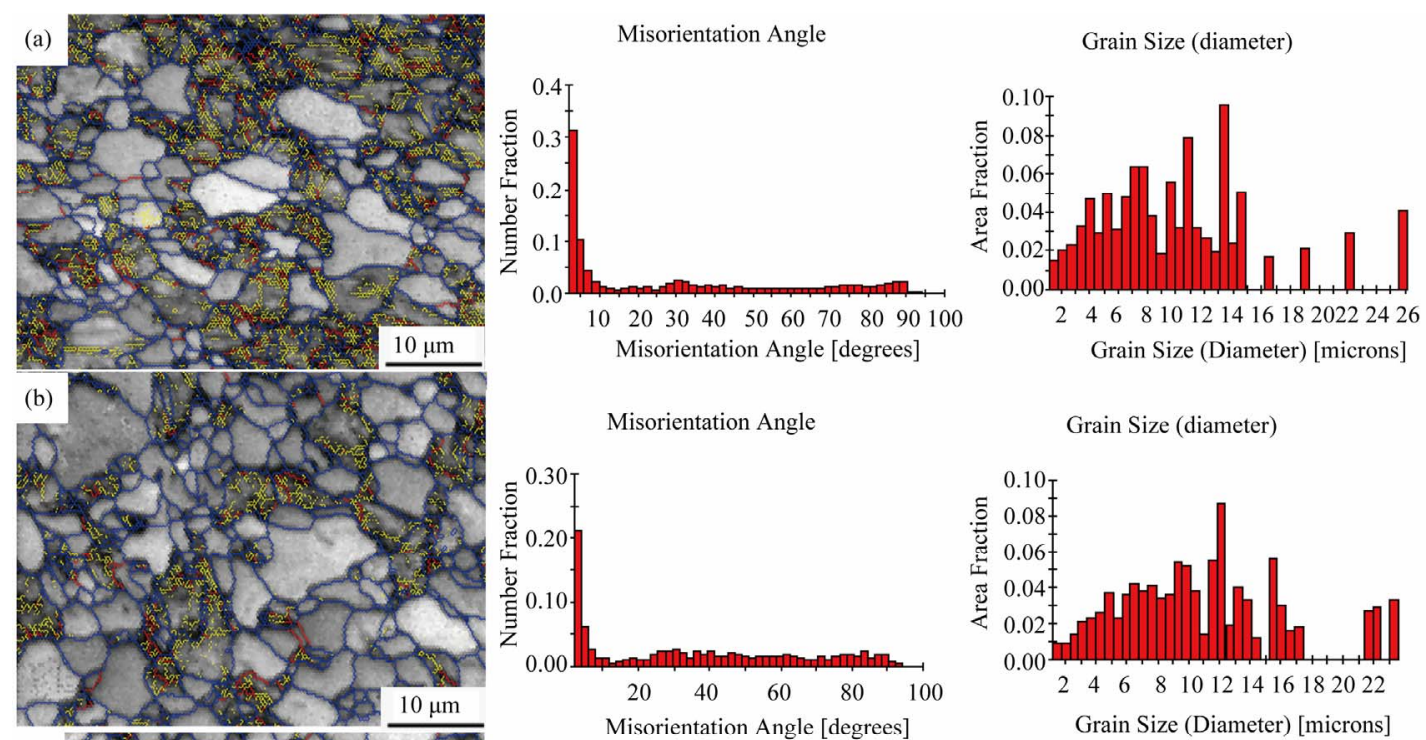

Grain Size (diameter)
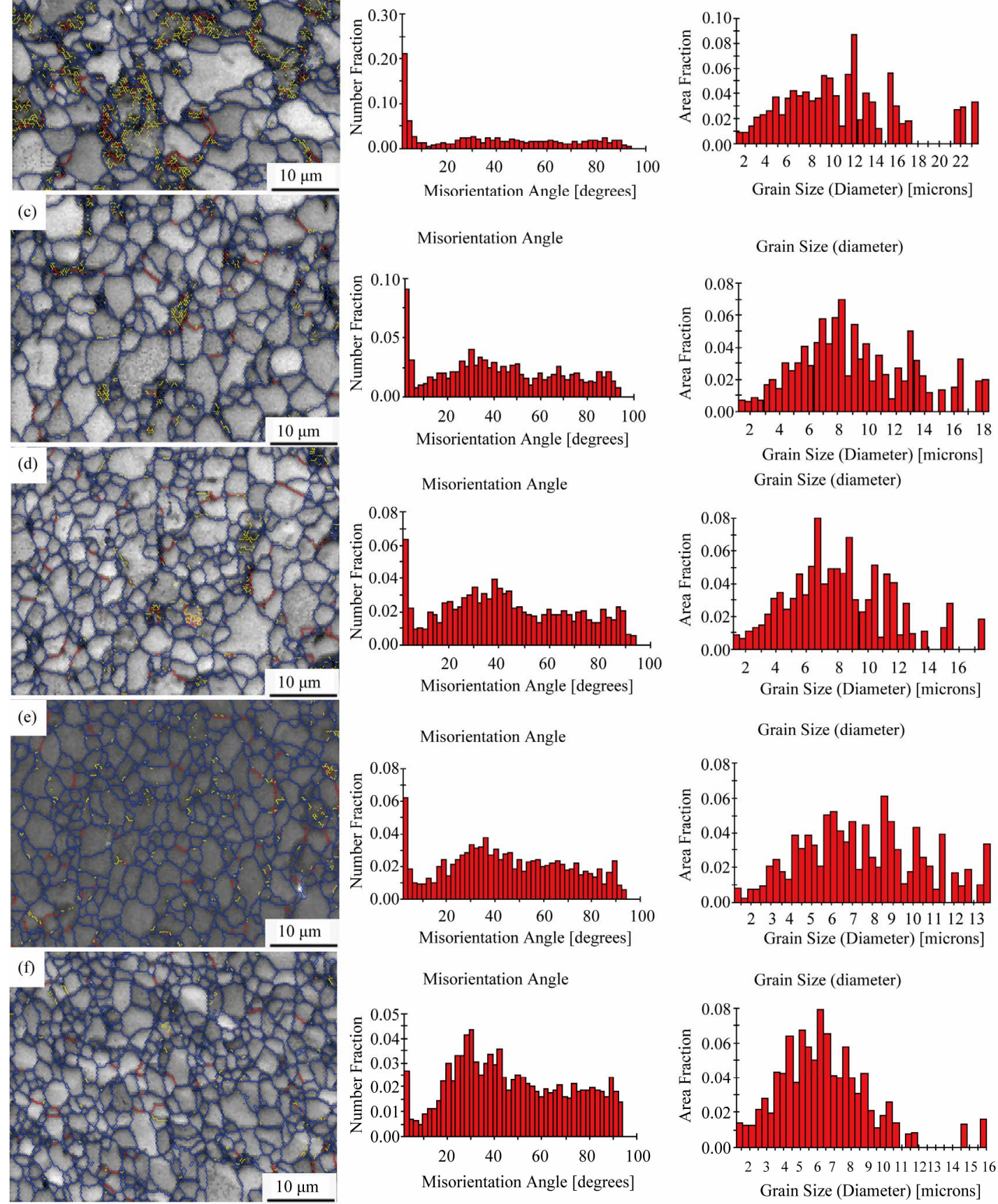

Grain Size (diameter)
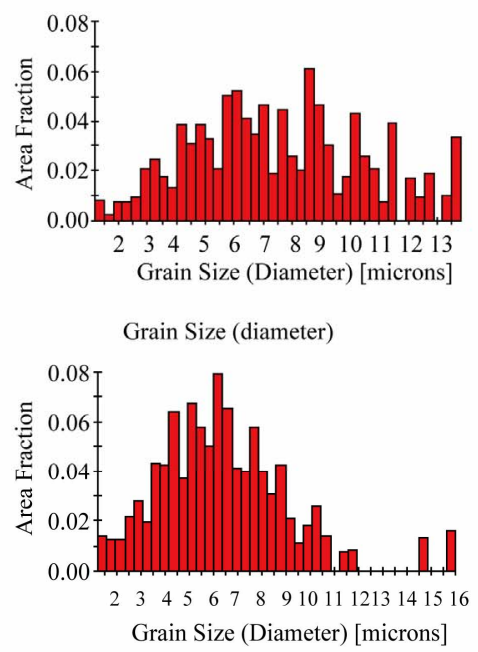

Figure 2. Microstructures, misorientation distribution and grain size distribution charts of the as-drawn wires. (a) 20\%; (b) $30 \%$; (c) $40 \%$; (d) $50 \%$; (e) $70 \%$; (f) $90 \%$. 

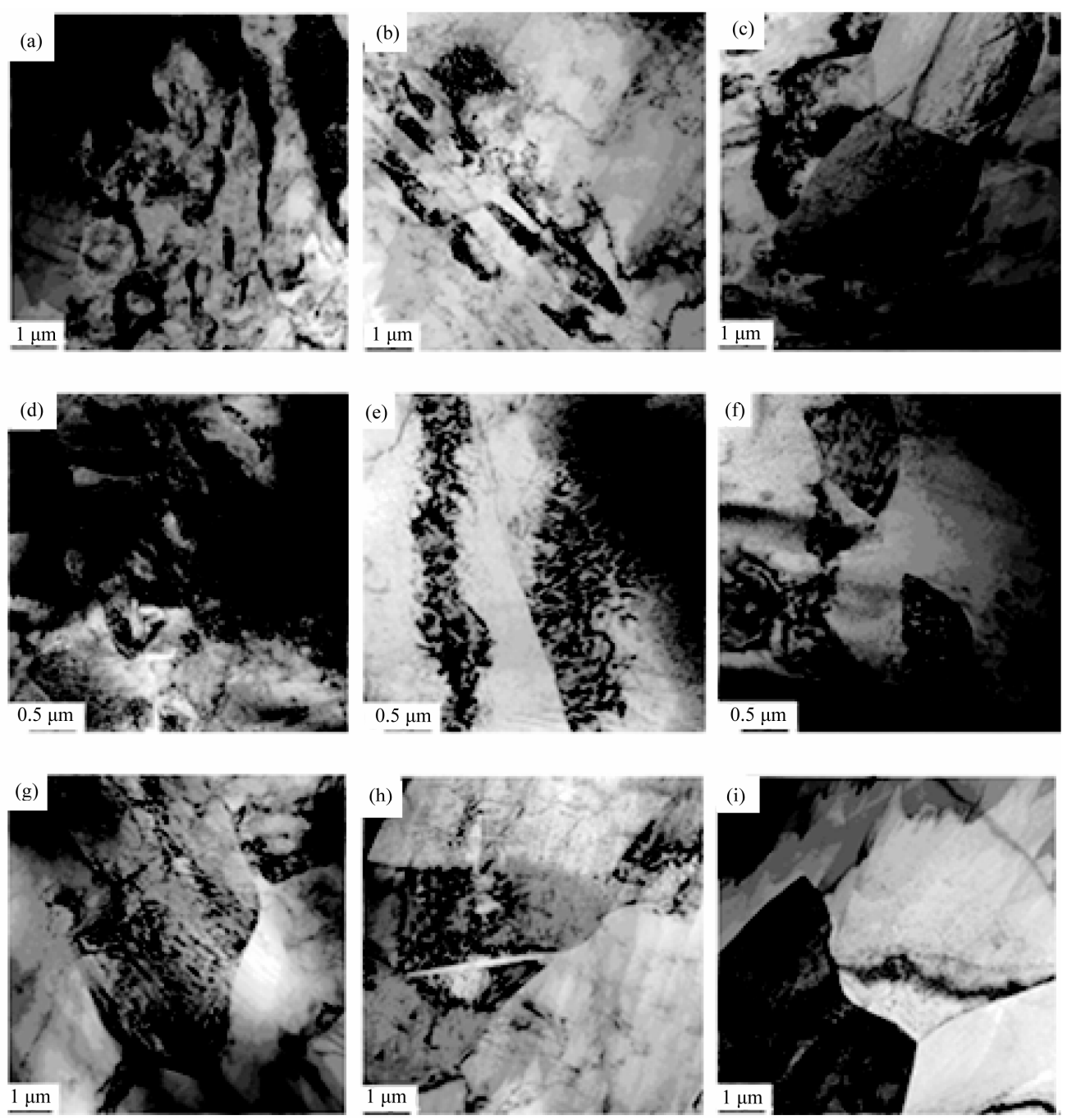

Figure 3. Microstructures of the as-drawn wires.

a recrystallization texture with basal plane (0002) and $<11-20>$ direction parallel to the drawing direction (DD), as shown in Figure 1. After the drawing process, the as-drawn wires showed a blended texture. Some grains showed deformation texture with basal plane (0002) and $<11-20>$ direction parallel to the drawing direction and some grains exhibited recrystallization texture with basal plane (0002) and $<11-20>$ direction parallel to the drawing direction, shown in Figure 4. From Figure 5, the grains boundaries with deformation texture were relatively straight, but the grains boundaries with recrystallization texture were relatively wavy. The proportion of the recrystallization texture declined with the drawing process, it can be seen from both Figures $\mathbf{4}$ and 5.

\subsection{Mechanical Properties}

Figure 6 shows the mechanical properties of the asdrawn wires. It can be seen that both the microhardness
(HV) and the tensile strengths, i.e., yield strengths (YS) and ultimate tensile strengths (UTS) increase with increasing cumulative area reduction at $\phi<30 \%$, while opposite for ductilities. With the cold drawing process keeping on, the microhardness, the tensile strengths and the ductilities of the as-drawn wires had not obviously changed. This phenomenon is very common during hot deformation due to dynamic recovery (DRV) and DRX but it is very peculiar in cold deformation. It can be speculated that DRV or DRX had taken place during the cold drawing process of pure Mg. Mechanical properties of AZ31 Mg alloy wires with the same drawing process are also shown in Figure 6; it shows an obvious strain hardening behavior during the cold drawing process.

\section{Discussion}

All the results mentioned above indicate that continuous DRX of pure $\mathrm{Mg}$ has taken place during successful drawing at room temperature. 


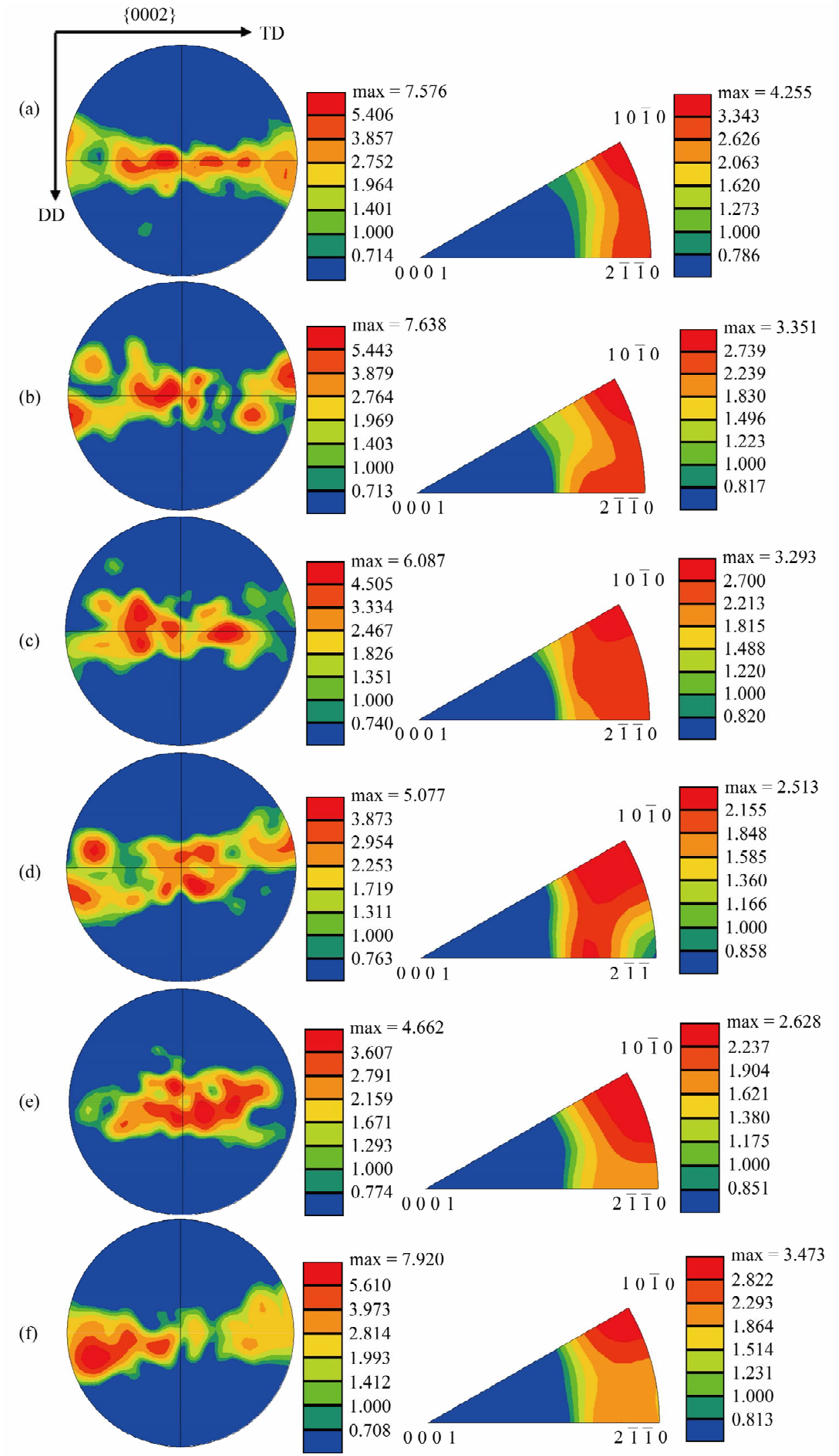

Figure 4. Changes in pole figures and inverse pole figures with different area reduction. (a) $20 \%$; (b) $30 \%$; (c) $40 \%$; (d) $50 \%$; (e) $70 \%$; (f) $90 \%$. (The samples direction of the inverse pole figures are drawing direction). 


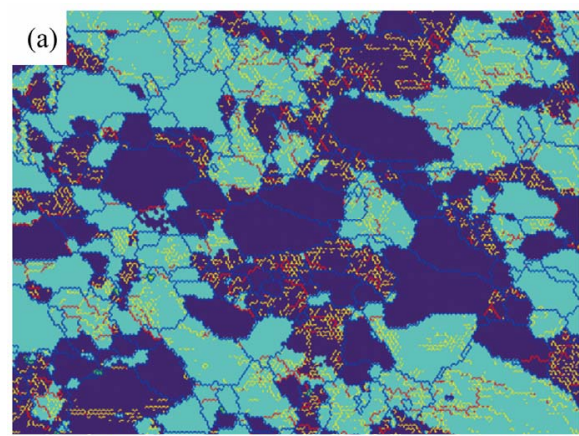

[100]
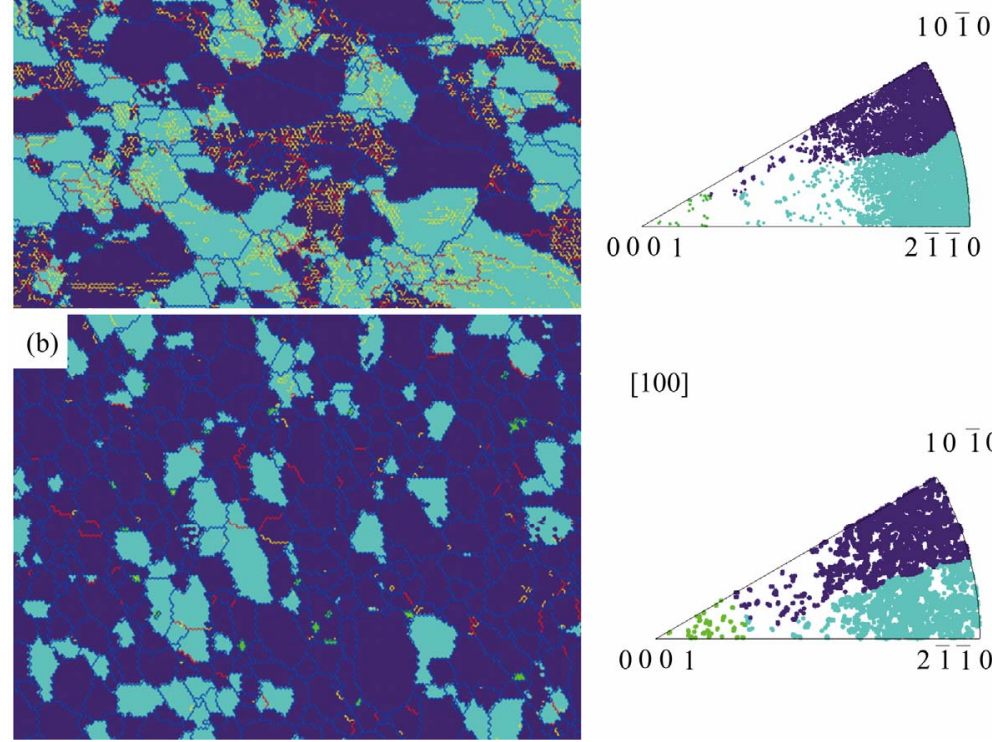

$[100]$

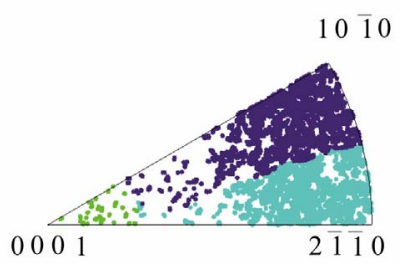

Figure 5. Inverse pole figures with different area reduction. (a) $20 \%$; (b) $90 \%$. (The samples direction of the inverse pole figures are drawing direction).
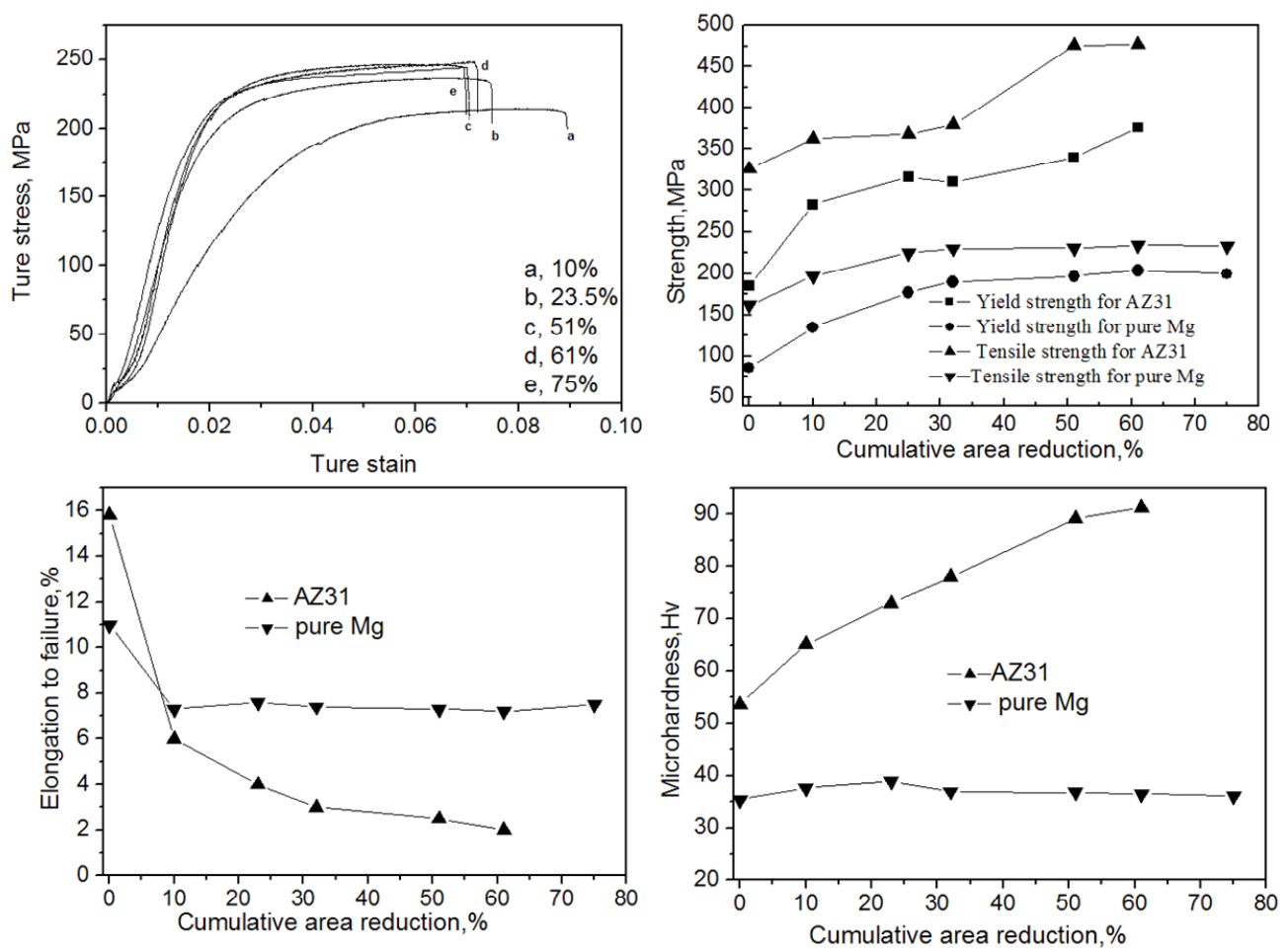

Figure 6. Mechanical properties of the as-drawn wires.

The characteristic of continuous DRX is that nucleation and growth stages of primary recrystallization do not occur. Various terms have been used to describe such micro structural transformations, including "continuous recrystallization" (the most widely used), "in-situ recrys- tallization" and "extended recovery" [12-17]. Restoration mechanism operated in continuous DRX is principally dynamic recovery $[18,19]$. This DRX primary takes place during deformation at low temperature, because of the energy needed to occur DRV is much lower than those of 
during discontinuous DRX. Deformation bands where the sub-boundary $\left(2^{\circ}-5^{\circ}\right.$ misorientation) is greater than that in the surrounding material are developed during deformation, as shown in Figure 7(a). With the deformation coming on, sub-boundaries turn into LAB $\left(5^{\circ}-15^{\circ}\right.$ misorientation) via dislocation motion and the development of higher angle boundaries by the merging of lower angle boundaries, as shown in Figures 7(b) and (c).

The $\sigma-\varepsilon$ curve controlled by dynamic recovery shows generally no work softening and only a steady state flow in high strain, as shown in Figure 8(a). The $\sigma-\varepsilon$ curve controlled by conventional DRX shows a single peak in relatively low strain and then a strain softening, followed by a stead state in high strain, as shown in Figure 5(b). The mechanical properties curves in this article confirmed that continuous DRX has taken place during cold drawing.

Why continuous DRX does not take place for AZ31 $\mathrm{Mg}$ alloy wires with the same processing? It has been reported that the DRX temperature for pure metals is higher than its alloys, i.e., the DRX temperature increases from $400^{\circ} \mathrm{C}$ to $440^{\circ} \mathrm{C}$ when adding $0.04 \% \mathrm{Li}$ element in pure $\mathrm{Cu}$. It has been reported that DRX is not observed in $99.99 \% \mathrm{Al}$, but is in $\geq 99.999 \% \mathrm{Al}$, because the mobility of the GB is so much enhanced by absence of impurities that it undergoes SRX at $20^{\circ} \mathrm{C}$ after cold working [20,21]. Alloy elements will obstruct the moving and arraying of dislocations, and will restrain nucleation and sliding of grain boundary during recrystallization. So the recrystallization temperature for alloy is much higher than pure metal. Hence, pure Mg exhibits an obvious DRX phenomenon during drawing at room temperature, while AZ31 $\mathrm{Mg}$ alloy shows an obvious strain hardening behaviors.

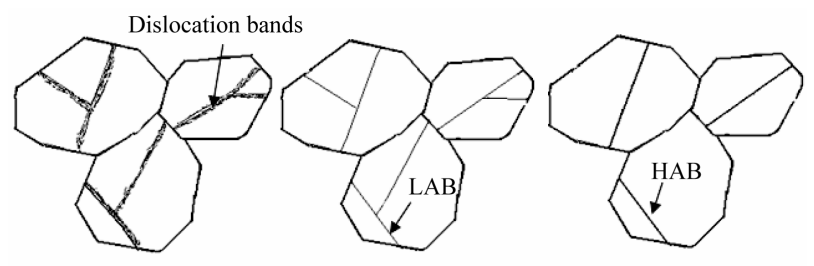

(a)

(b)

(c)

Figure 7. Diagram for CDRX of Mg alloy.

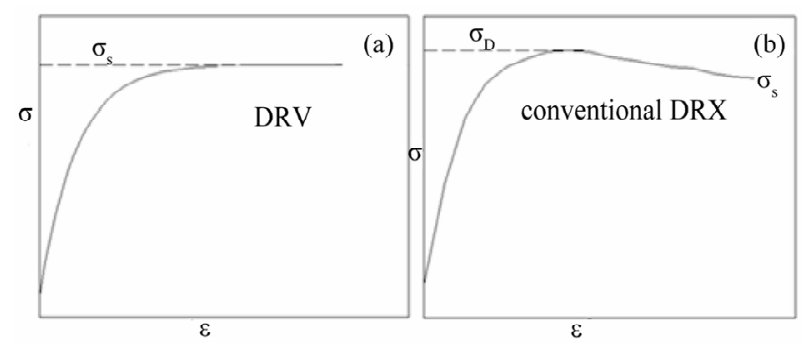

Figure 8. $\sigma-\varepsilon$ curves controlled by DRV (CDRX) and conventional DRX.

\section{Conclusions}

The main results obtained in this article are as follows:

1) Pure $\mathrm{Mg}$ wires with a cumulative area reduction of $98 \%$ were obtained using successful cold drawing.

2) When the cumulative area reduction exceeds $30 \%$, all the mechanical properties have not obviously changed. It is a symbol of DRX.

3) The microstructure evolution confirms the conclusion and how the whole process of DRX: nucleation and grain growth.

\section{REFERENCES}

[1] B. L. Mordike, T. Ebert, "Magnesium: Properties-Applications-Potential," Materials Science and Engineering: A, Vol. 302, No. 1, 2001, pp. 37-45. doi:10.1016/S0921-5093(00)01351-4

[2] A. Styczynski, C. Hartig, J. Bohlen and D. Letzig, "Cold Rolling Textures in AZ31 Wrought Magnesium Alloy," Scripta Materialia, Vol. 50, No. 7, 2004, pp. 943-947. doi:10.1016/j.scriptamat.2004.01.010

[3] H. Y. Wu and F. Z. Lin, "Mechanical Properties and StrainHardening Behavior of Mg Alloy AZ31B-H24 Thin Sheet," Materials Science and Engineering: A, Vol. 527, No. 4-5, 2010, pp. 1194-1199. doi:10.1016/j.msea.2009.09.049

[4] Z. Trojanova, Z. Drozd, P. Lukac and F. Chmelik, "Deformation Behaviour of Mg-Li Alloys at Elevated Temperatures," Materials Science and Engineering: A, Vol. 410-411, 2005, pp. 148-151. doi:10.1016/j.msea.2005.08.088

[5] T. Samman and G. Gottstein, "Room Temperature Formability of a Magnesium AZ31 Alloy: Examining the Role of Texture on the Deformation Mechanisms," Materials Science and Engineering: A, Vol. 488, No. 1-2, 2008, pp. 406-414. doi:10.1016/j.msea.2007.11.056

[6] Y. Chino, H. Iwasaki and M. Mabuchi, "Stretch Formability of AZ31 Mg Alloy Sheets at Different Testing Temperatures," Materials Science and Engineering: A, Vol. 466, No. 1-2, 2007, pp. 90-95. doi:10.1016/j.msea.2007.02.027

[7] C. H. Caceres and A. H. Blake, "On the Strain Hardening Behaviour of Magnesium at Room Temperature," Materials Science and Engineering: A, Vol. 462, No. 1-2, 2007, pp. 193-196. doi:10.1016/j.msea.2005.12.113

[8] S. E. Ion, F. J. Humphreys and S. H. White, "Dynamic Recrystallisation and the Development of Microstructure during the High Temperature Deformation of Magnesium," Acta Metallurgica, Vol. 30, No. 10, 1982, pp. 19091919. doi:10.1016/0001-6160(82)90031-1

[9] R. Kaibyshev and O. Sitdikov, "Recrystallization and Related Phenomena (ReX'96)," MIAS, Vol. 20, 1997, pp. 287-294.

[10] A. Galiyev, R. Kaibyshev and G. Gottstein, "Correlation of Plastic Deformation and Dynamic Recrystallization in Magnesium Alloy ZK60," Acta Materialia, Vol. 49, No. 7, 2001, pp. 1199-1207. doi:10.1016/S1359-6454(01)00020-9 
[11] O. Sitdikov, K. Kaibyshev and T. Sakai, "Dynamic Recrystallization Based on Twinning in Coarse-Grained Mg," Materials Science Forum, Vol. 419-422, 2003, pp. 521526. doi:10.4028/www.scientific.net/MSF.419-422.521

[12] E. Hormbogen and U. Koster, In: F. Haessner, Riederer, Eds., Materials, Verlag, Berlin, 1978, p. 159.

[13] E. Hornbogen, "Combined Reactions," Metallurgical Transactions A, Vol. 10, No. 8, 1979, pp. 947-972. doi:10.1007/BF02811643

[14] H. J. McQueen and J. J. Jonas, "Treatise on Materials Science and Technology," In: R. J. Arsenault, Ed., Vol. 6, Academic Press, New York, 1975, pp. 393-493.

[15] E. Nes, "Strain-Induced Continuous Recrystallization in Zr-Bearing Aluminium Alloys," Journal of Materials Science, Vol. 13, No. 9, 1978, pp. 2052-2055. doi:10.1007/BF00552917

[16] E. Nes, Metal Science Journal, Vol. 13, 1979, pp. 211220.

[17] R. D. Doherty, G. Gottstein, J. Hirsch, W. B. Hutchinson, K. Lucke, E. Nes and P. J. Wilbrandt, Proc. ICOTOM8, TMS, Warrendale, 1988, pp. 563-572.
[18] F. J. Humphreys and M. Hatherly, "Recrystallization and Related Annealing Phenomena," Oxford, Pergamon, 1995, pp. 120-123.

[19] X. Yang, H. Miuna and T. Sakai, "Dynamic Evolution of New Grains in Magnesium Alloy AZ31 during Hot Deformation," Materials Transactions, Vol. 44, No. 1, 2003, pp. 197-203. doi:10.2320/matertrans.44.197

[20] H. Yamagata, "In Situ Observation of Dynamic Recrystallization in Five-Nine Aluminum by a Transmission Laue Method," Scripta Metallurgica et Materialia, Vol. 30, No. 4, 1994, pp. 411-416. doi:10.1016/0956-716X(94)90595-9

[21] M. E. Kassner, H. J. McQueen, J. Pollard, E. Evangelista and E. Cerri, "Restoration Mechanisms in Large-Strain Deformation of High Purity Aluminum at Ambient Temperature," Scripta Metallurgica et Materialia, Vol. 31, No. 10, 1994, pp. 1331-1336. doi:10.1016/0956-716X(94)90113-9 